\title{
Pre-breakdown streamer propagation and breakdown characteristics of refined bleached and deodorized palm oil under lightning impulse voltage
}

\begin{abstract}
This paper presents the investigation on the breakdown characteristics and pre-breakdown streamer propagation of Palm Oil (PO) impregnated aged pressboard under positive lightning impulse voltages. The experimental work was carried out under a non-uniform field with needle-plane electrodes configuration. The streamer stopping length and breakdown voltage of 2 types of refined, bleached, and deodorized palm oil were examined in the presence of new and aged pressboards. The pressboard was placed in parallel to the needle-plane electrode at a gap distance of $50 \mathrm{~mm}$. The lightning breakdown voltage was applied to the samples based on 1 shot per step rising voltage method under positive polarity as per IEC 60897. The presence of impregnated pressboard in both PO slightly increases the $50 \%$ positive lightning breakdown voltages. PO impregnated pressboards have lower $50 \%$ positive lightning breakdown voltages than MO. After subjected to ageing, the positive lightning breakdown voltages for $\mathrm{PO}$ and $\mathrm{MO}$ impregnated pressboards decrease. In the presence of aged pressboard, the streamers in PO generally propagate further than MO at the same voltage level.
\end{abstract}

Keyword: Lightning impulse breakdown voltage; Non-uniform field; Palm oil; Aged pressboard; Streamer characteristics; Transformers 